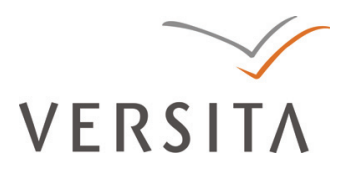

Folia Oeconomica Stetinensia

DOI: $10.2478 / \mathrm{v} 10031-012-0015-8$

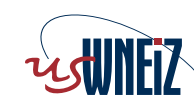
Wydzial Nauk Ekonomicznych i Zarządzania
Uniwersytetu Szczecińskiego

\title{
THE COST OF INFORMATION IN DEPENDENCE \\ ON THE INVESTOR RELATION TO THE RISK
}

\author{
Simona Hašková Ing. \\ University of Economics in Prague \\ Faculty of Management \\ Department of Business Management \\ Jarošovská 1117, 37701 Jindřichův Hradec, Czech Republic \\ E-mail: haskovas@post.cz
}

Received 14 May 2012, Accepted 16 November 2012

\begin{abstract}
The contribution sets simple mathematic models describing and explaining the way of behavior of various types of investors (the private and institutionalized ones). The models come from the cardinal utility theory which is used for explaining the connection between the subjective relationship towards risk and some pathologic phenomenon of finance theory (for example the moral hazard question of institutionalized investors) and takes into account the decision making of both ordinary people and professional investors. A reliable estimate of the economic surroundings where the investment should run contributes significantly to a quality of the particular investment decisions. The article contributes to a quality of the investment decision by the original and primary approach to pricing information that lowers the uncertainty in occurrences of the relevant scenarios of the project's development. At the conclusion there is shown how the shift of the decision breaking point shapes the amount of the acceptable price of the information.
\end{abstract}

Keywords: Expected net present value, uncertainty and risk, Shannon entropy, pricing of information.

JEL classification: D81. 


\section{Introduction}

The contribution deals with the behavior of investors at the moment of the decision-making process concerning purchasing the product (a product investment). By a product we understand both a project (a business plan) and a financial (money and capital) market instrument including the property market (that is a deposit, a loan, a mortgage, securities etc.).

The investment is an act in which we take into consideration the price of a product (the capital expenditure $\mathrm{C}_{0}$, which in case of a loan or a mortgage is the present value (PV) of the future installments) and a contemplated outcome ${ }^{1}$. The character of an outcome can be a final one or a transitive one. As for the final outcome we consider a result stated in gross or net form (the present value (PV) or the net present value (NPV) of cash flows resulting from a purchased product). The transitive outcome is meant to be another investment procured from the gross result of the previous one ${ }^{2}$. In such a concept of an investment it is typical for an institutionalized investor (in contrast to a private one) to invest predominantly the loan capital ${ }^{3}$. The typical institutionalized investor is, for instance, a bank.

Firstly, we formulate a mathematic model of an investment, in which we explain the difference between the utility of a certain wealth and the expected utility of an unbiased estimate of the same value of that wealth. Then we introduce the risk averse behavior of investors in the graphic presentation of the utility function for wealth and point at required corrections that the consideration of financial risk of investment takes in the NPV rule. Finally, we reveal why banks, where the state guarantees the creditors' deposits, invest in the way they invest.

\section{The mathematic model of investment}

This presented model of an investment comes out of the general model of a lottery ${ }^{4}$ and, besides the uncertainty of the outcome, develops it in the manner of taking into account the financial risk resulting from the variability of a return rate ${ }^{5}$ that is included in the PV and NPV calculation. The inclusion is performed by either the nominal values of cash flow adjustments (the certainty-equivalent method) or by the discount rate increase of so-called risk-premium (the model CAPM - capital asset pricing model). We get the same result in both cases ${ }^{6}$. An investment $\boldsymbol{I}$ is the particular lottery gamble ${ }^{7}$ which takes on two possible outcomes (prizes) $\mathbf{x}$ and $\mathbf{y}$ with probabilities $\mathbf{p}$ and $(\mathbf{1}-\mathbf{p})$. Its formal notation is

$$
I: \mathrm{p}^{\circ} \mathrm{x} \square(1-\mathrm{p})^{\circ} \mathrm{y}
$$


which means: by the realization of an investment the investor receives either the outcome $\mathbf{x}$ with probability $\mathbf{p}$ or the outcome $\mathbf{y}$ with probability $(\mathbf{1}-\mathbf{p})$. Figure 1 illustrates the possible outcomes through some of the binary trees where $-\mathrm{C}_{0}$ marks the initial capital expenditure (the price of the investment):

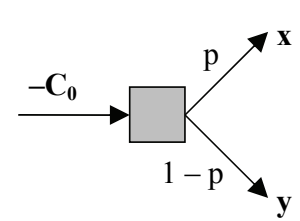

a)

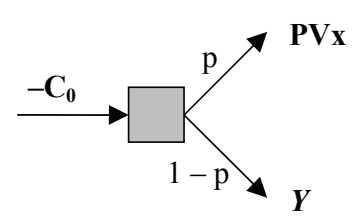

b)

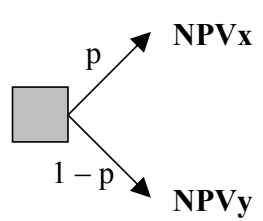

c)

Fig. 1. The possible graph representations of the investments model Source: own model.

As we mentioned in the introduction, the outcome can be the result (in gross or net form) or another investment. If the outcome is not specified we label it with a small letter (see Figure 1a). If the outcome is an investment it is labeled with a capital letter. In the case of the gross form result it is given by its PV value (see Figure 1b). If all of the outcomes are final ones thus because of NPV $=-\mathrm{C}_{0}+\mathrm{PV}$ we can state them in the net form through their net present values (NPV - see Figure 1c). The probability of a result is given by the probability of incidence of an assumed scenario development in which framework the result is estimated. The probability of the next investment is the degree of anticipation ${ }^{8}$ with which the gross result of the previous investment will be reinvested into this investment ${ }^{9}$.

\subsection{Reduction and composition of investments}

The model of lottery comes out of the following elementary assumptions ${ }^{10}$ :

$-\mathrm{p}^{\circ} \mathrm{x} \square(1-\mathrm{p})^{\circ} \mathrm{y} \sim(1-\mathrm{p})^{\circ} \mathrm{y} \square \mathrm{p}^{\circ} \mathrm{x} \ldots$...(the order in which the lottery is described is irrelevant),

$-1 \circ \mathrm{x} \square(1-1)^{\circ} \mathrm{y} \sim \mathrm{x} \ldots$ (there is only one certain outcome),

$-\mathrm{q}^{\circ}\left(\mathrm{p}^{\circ} \mathrm{x} \square(1-\mathrm{p})^{\circ} \mathrm{y}\right) \square(1-\mathrm{q})^{\circ} \mathrm{y} \sim(\mathrm{q} \cdot \mathrm{p})^{\circ} \mathrm{x} \square(1-\mathrm{q} \cdot \mathrm{p})^{\circ} \mathrm{y} \ldots$...(the reduction of compound lotteries illustrated in Figure 2).

The equivalence $(\sim)$ between the expressions in the third assumption defines the rule of reduction of compound lotteries to a single lottery (one-shot lottery) in the particular case with two possible results $\mathrm{x}$ and $\mathrm{y}$. The rule respects the incompatibility of the same results at various 
re-runs of the attempt and its mutual dependence $(y \cdot(q \cdot(1-p)+(1-q))=y \cdot(q-q \cdot p+1$ $-\mathrm{q})=y \cdot(1-\mathrm{q} \cdot \mathrm{p}))$; at the same time it proceeds from the assumption that the gambler treats the lottery just and only according to the final results and their probabilities and he does not care about the time factor too much. However, it is the time factor that causes the different gamblers' perception of one-shot lotteries and compound lotteries.
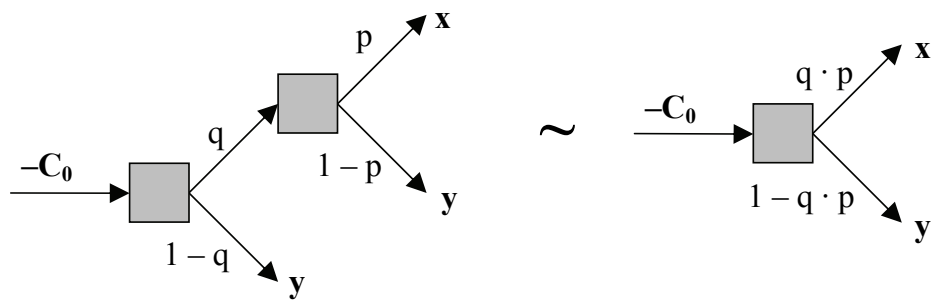

Fig. 2. Reduction of compound lotteries

Source: own model.

The investor, on the other hand, regards each investment according to its expected net present value (E[NPV]), which is the unbiased estimate of the net result of the investment. The time factor (as well as the risk rate) is relevantly respected in it and that is why the above mentioned difference in gamblers' perception of lotteries does not occur here.

The rule of composition can be attained by reversing the use of the reduction rule which enables us to put together the one-shot investments of arbitrary numbers of outcomes out of the two unrepeatable investment outcomes - see the following examples of generating the three and four investment outcomes:

- If $X: r^{\circ} \mathrm{W} \square(1-\mathrm{r})^{\circ} \mathrm{z}$ then $\mathrm{p}^{\circ} X \square(1-\mathrm{p})^{\circ} \mathrm{y}=\mathrm{p}^{\circ}\left(\mathrm{r}^{\circ} \mathrm{W} \square(1-\mathrm{r})^{\circ} \mathrm{z}\right) \square(1-\mathrm{p})^{\circ} \mathrm{y} \sim$ $\mathrm{p} \cdot \mathrm{r}{ }^{\circ} \mathrm{W} \square \mathrm{p} \cdot(1-\mathrm{r})^{\circ} \mathrm{z} \square(1-\mathrm{p})^{\circ} \mathrm{y}$,

- if $\boldsymbol{Y}: \mathrm{q}^{\circ} \mathrm{u} \square(1-\mathrm{q})^{\circ} \mathrm{v}$ then $\mathrm{p}^{\circ} \mathrm{X} \square(1-\mathrm{p})^{\circ} Y=\mathrm{p}^{\circ} \mathrm{X} \square(1-\mathrm{p})^{\circ}\left(\mathrm{q}^{\circ} \mathrm{u} \square(1-\mathrm{q})^{\circ} \mathrm{v}\right) \sim$ $\mathrm{p}^{\circ} \mathrm{X} \square(1-\mathrm{p}) \cdot \mathrm{q}^{\circ} \mathrm{u} \square(1-\mathrm{p}) \cdot(1-\mathrm{q})^{\circ} \mathrm{v}$,

- if $\boldsymbol{X}$ : row $\square(1-\mathrm{r})^{\circ} \mathrm{Z}$ and $\boldsymbol{Y}: \mathrm{q}^{\circ} \mathrm{u} \square(1-\mathrm{q})^{\circ} \mathrm{v}$ then

$$
\begin{aligned}
& \mathrm{p}^{\circ} X \square(1-\mathrm{p})^{\circ} Y=\mathrm{p}^{\circ}\left(\mathrm{r}^{\circ} \mathrm{W} \square(1-\mathrm{r})^{\circ} \mathrm{z}\right) \square(1-\mathrm{p})^{\circ}\left(\mathrm{q}^{\circ} \mathrm{u} \square(1-\mathrm{q})^{\circ} \mathrm{v}\right) \sim \\
& \mathrm{p} \cdot \mathrm{r}^{\circ} \mathrm{W} \square \mathrm{p} \cdot(1-\mathrm{r})^{\circ} \mathrm{Z} \square(1-\mathrm{p}) \cdot \mathrm{q}^{\circ} \mathrm{u} \square(1-\mathrm{p}) \cdot(1-\mathrm{q})^{\circ} \mathrm{V} .
\end{aligned}
$$

This approach is well defined which proves the fact that $p \cdot r+p \cdot(1-r)+(1-p)=p+$ $(1-p) \cdot q+(1-p) \cdot(1-q)=p \cdot r+p \cdot(1-r)+(1-p) \cdot q+(1-p) \cdot(1-q)=1$. The graphic representation of the last instance (generating the one-shot four investment outcomes) is shown in Figure 3. 

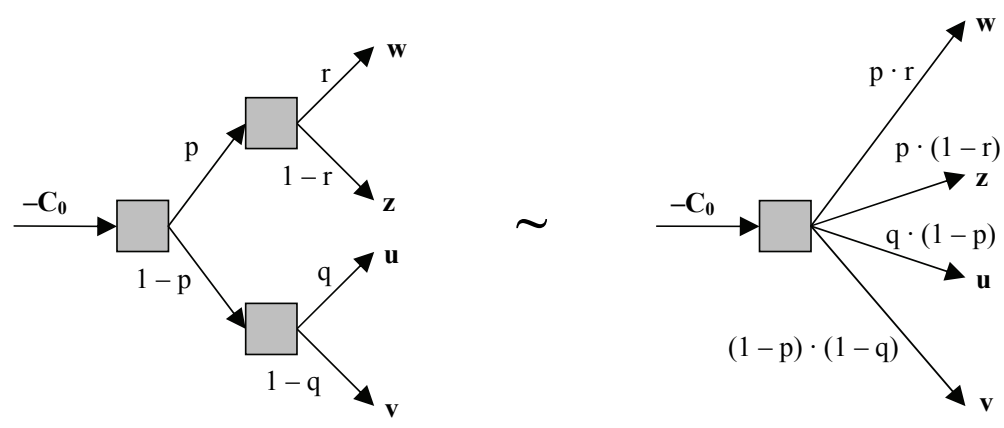

Fig. 3. The structure of composition of four investment outcomes Source: own model.

As shown, if we take a transitive outcome into account considering only two outcomes of the investment is not a restriction but a benefit. It allows us to deal with the investments of only two results in the net form extracted from the optimistic and pessimistic scenario, that is investments of the type $\mathbf{I}: \mathbf{p} \circ \mathbf{N P V}$ opt $\square(\mathbf{1}-\mathbf{p}) \circ \mathbf{N P V} \mathbf{p}_{\text {pes }}$ and the conclusions of our considerations in agreement with the performed composition of investments to transfer (generalize) to investments with greater number of results.

\subsection{The Shannon conception of the entropy of an investment with regard to uncertainty and the risk}

It is obvious that the investment $I: \mathrm{p}^{\circ} \mathrm{NPV}_{\text {opt }} \square(1-\mathrm{p}) \circ \mathrm{NPV}_{\text {pes }}$ (as well as the lottery) is a random attempt with two uncertain results. ${ }^{11}$ The expected net result $\mathrm{E}\left[\mathrm{NPV}_{\mathrm{I}}\right]=\mathrm{p} \cdot \mathrm{NPV}_{\mathrm{opt}}+$ $(1-\mathrm{p}) \cdot \mathrm{NPV}_{\mathrm{pes}}$ of this investment is connected with uncertainty that in the Shannon conception (so-called the entropy of random attempt ${ }^{12}$ ) takes on the value:

$$
H=-p \cdot(\lg p)-(1-p) \cdot(\lg (1-p))
$$

where $\lg$ marks the logarithm to the base 2. The unit of such a defined uncertainty is the average uncertainty of a result of a toss-up. It is the highest uncertainty that can be related to the investment $(\mathrm{H}=1)$ and it appears if both of the results are equally probable (uncertain).

The information and uncertainty in the Shannon conception are the complementary terms (the amount of information contained in the message is given by the amount of removed uncertainty by the message). The additional information benefit of the reliability of the considered scenarios of possible development ${ }^{13}$ lies in the fact that additional information changes the prior distribution over scenarios and so the prior distribution over the results of an 
investment $I$, which changes the original $\mathrm{E}\left[\mathrm{NPV}_{\mathrm{I}}\right]$ about $\Delta \mathrm{E}\left[\mathrm{NPV}_{\mathrm{I}}\right]$. The decision breaking point of an investor is when $\mathrm{E}\left[\mathrm{NPV}_{\mathrm{I}}\right]=0$. The investor accepts the investment if $\mathrm{E}\left[\mathrm{NPV}_{\mathrm{I}}\right]>0$ and he refuses it if $\mathrm{E}\left[\mathrm{NPV}_{\mathrm{I}}\right]<0$. If $\left|\Delta \mathrm{E}\left[\mathrm{NPV}_{\mathrm{I}}\right]\right|<\left|\mathrm{E}\left[\mathrm{NPV}_{\mathrm{I}}\right]\right|$, the additional information is irrelevant (it does not affect the decision), and it does not pay off to retrieve it. If it is relevant (it can affect the decision) then, as it is shown in the following part 1.3, its price should not exceed the value of $\left|\Delta \mathrm{E}\left[\mathrm{NPV} \mathrm{V}_{\mathrm{I}}\right]\right|-|\mathrm{E}[\mathrm{NPV} \mathrm{I}]|$.

The uncertainty and the uncertain estimate resulting from it is the basic feature of a random attempt. Moreover, if the possible results of an attempt differ on its quality in sense of some of them being desirable and others undesirable we talk rather about risk than uncertainty. If all results are either desirable or undesirable, we do not usually talk about risk. The investment I: $\mathrm{p}^{\circ} \mathrm{NPV} \mathrm{opt} \square(1-\mathrm{p}){ }^{\circ} \mathrm{NPV}_{\text {pes }}$ is thus risky in the case of $\mathrm{NPV}_{\text {opt }}>0$ and $\mathrm{NPV}_{\text {pes }}<0$. The values of investors' wealth converted to the present (the variable $\mathrm{M}$ ) are plotted in Figure 4 together with other details that relate to the analysis of the risk investment $I$.

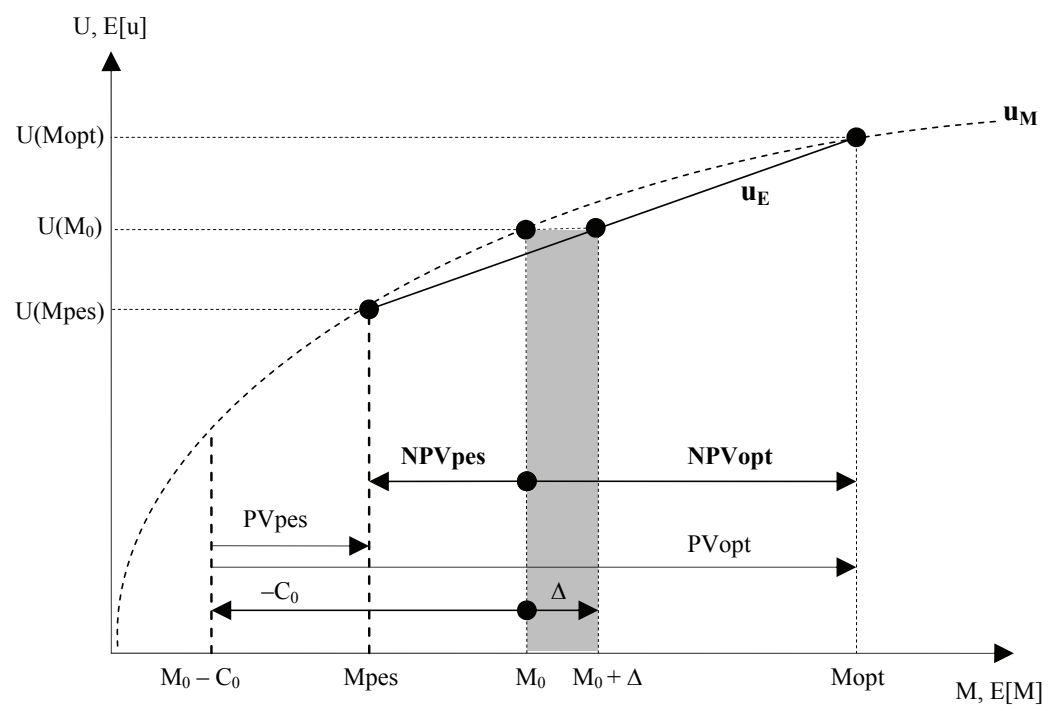

Fig. 4. The analysis of the risk investment within the utility maximization criterion Source: own model.

$\mathrm{M}_{0}$ stands for the initial value of the total investor's wealth. If he decides for the investment $I$, then at the moment of paying its price $C_{0}$ his wealth drops to $\mathrm{M}_{0}-\mathrm{C}_{0}$ with a promise of a followup increase to $\mathrm{M}_{\mathrm{opt}}$ in the better case, in the worse case to $\mathrm{M}_{\text {pes }}$. The unbiased estimate of the final value of his total wealth (after the payoff from the investment $I$ ) $\mathrm{E}\left[\mathrm{M}_{\mathrm{I}}\right]=\mathrm{M}_{0}+\mathrm{E}\left[\mathrm{NPV}_{\mathrm{I}}\right]$ is 
not recorded on the axis $\mathrm{M} . \mathrm{E}\left[\mathrm{M}_{\mathrm{I}}\right] \in\left\langle\mathrm{M}_{\text {pes }}, \mathrm{M}_{\text {opt }}\right\rangle$ and if, for instance, $\mathrm{p}=0.5, \mathrm{E}\left[\mathrm{M}_{\mathrm{I}}\right]$ would lie in the middle of the interval $\left\langle\mathrm{M}_{\mathrm{pes}}, \mathrm{M}_{\mathrm{opt}}\right\rangle$. The fact that even $\mathrm{M}_{0} \in\left\langle\mathrm{M}_{\mathrm{pes}}, \mathrm{M}_{\mathrm{opt}}\right\rangle$ indicates the risk investment is a consequence of $\mathrm{NPV}_{\text {opt }}>0$ and $\mathrm{NPV}_{\text {pes }}<0$. From a different point of view it is a consequence of $\mathrm{PV}_{\text {pes }}<\mathrm{C}_{0}<\mathrm{PV}_{\text {opt }}$ (see Figure 4). If $\mathrm{C}_{0}<\mathrm{PV}_{\text {pes }} \Rightarrow \mathrm{M}_{0}<\mathrm{M}_{\text {pes }}$ or $\mathrm{C}_{0}>\mathrm{PV}_{\text {opt }} \Rightarrow$ $\mathrm{M}_{0}>\mathrm{M}_{\mathrm{opt}}$ thus the investment $I$ would not be the risk investment.

The gross results do not depend on $\mathrm{C}_{0}$ and so (as shown in Figure 4) a change of $\mathrm{C}_{0}$ alters the location of the interval $\left\langle\mathrm{M}_{\mathrm{pes}}, \mathrm{M}_{\mathrm{opt}}\right\rangle$ with respect to $\mathrm{M}_{0}$, which moves the tightly connected value $E\left[M_{I}\right]$ to the interval and thus alters the value $E\left[N V_{I}\right]$ as well. It is obvious from Figure 4 that the interval $\left\langle\mathrm{M}_{\mathrm{pes}}, \mathrm{M}_{\mathrm{opt}}\right\rangle$ can be pushed to the left without a change of $\mathrm{C}_{0}$ (with all the mentioned effects) by either increasing the discount rate or by reducing the certainty-equivalents of the gross result values.

\subsection{Pricing of information}

Let us suppose the initial situation marked in Figure 5 by underlining. There are two possible outcomes $\mathrm{NPV}_{\text {pes }}$ and $\mathrm{NPV}_{\text {opt }}$ of the investment $I$. As we do not know anything about their occurrences we regard them as equally probable $(p=1-p=0.5)$ in the first draft. The Shannon entropy of the investment $I$ reaches the maximum value $\mathrm{H}=1$ and for the initial estimate of the expected net present value it holds: $E\left[N P V_{I}\right]=\left(N P V_{\text {pes }}+N P V_{\text {opt }}\right) / 2$.

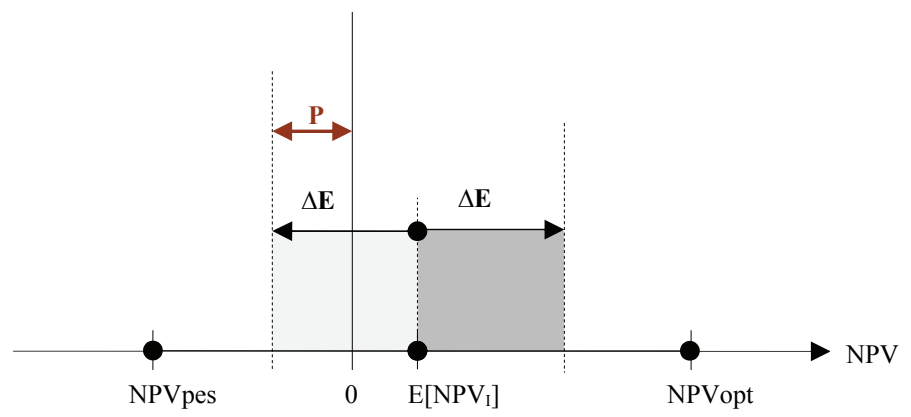

Fig. 5. The graphic representation of the upper limit estimate of the acceptable price for information

Source: own model.

Then let us suppose that we know there is a piece of knowledge that is not free of charge at disposal that would lower the initial entropy about $\Delta H(0<\Delta H<1)$. The question is:

„For what price does it pay one off to get this information? “ 
We answer the question with help of the graph describing the dependence $\mathrm{H}$ on $\mathrm{p}$ introduced in Figure 6. There we can see that lowering the initial entropy about $\Delta \mathrm{H}$ is a consequence of the change of the initial probability $\mathrm{p}=0.5$ about $\Delta \mathrm{p}$ in favor of one of the possible results. If the knowledge brings a greater chance for the result $\mathrm{NPV}_{\text {opt }}$, it directs $\Delta \mathrm{p}$ to the right, if it be to the contrary it directs $\Delta \mathrm{p}$ to the left.

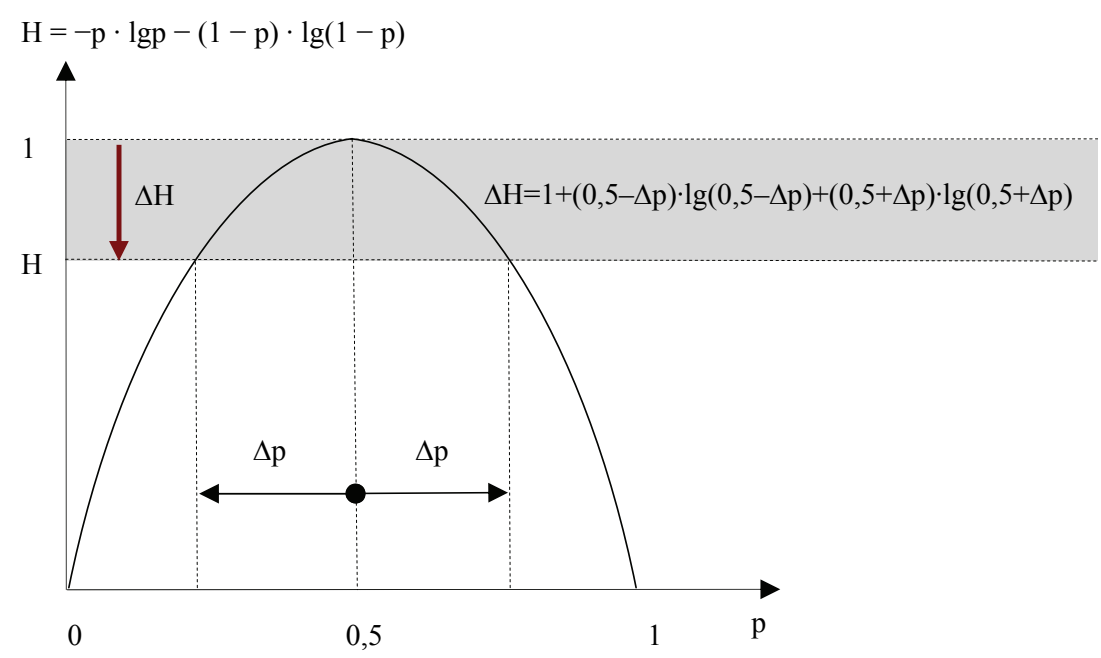

Fig. 6. The graph of dependence $\mathrm{H}$ on $\mathrm{p}$

Source: own model.

If we lower the initial $\mathrm{H}=1$ about the value $\Delta \mathrm{H}$ (the width of the grey colored stripe) in the graph on the vertical axis we gain the adequate non negative number $|\Delta p| \in\langle 0,0.5\rangle$ on the horizontal axis that sets the length of the arrow connected with $\Delta \mathrm{p}$. We find it out and calculate the value $\Delta \mathrm{E}=|\Delta \mathrm{p}| \cdot\left(\mathrm{NPV}_{\text {opt }}-\mathrm{NPV}_{\text {pes }}\right)$. It is obvious that $\Delta \mathrm{E}=\left|\Delta \mathrm{E}\left[\mathrm{NPV} \mathrm{I}_{\mathrm{I}}\right]\right|^{14}$ After getting the piece of knowledge the initial $\mathrm{E}\left[\mathrm{NPV}_{\mathrm{I}}\right]$ shifts about $\Delta \mathrm{E}$ to the right or to the left (see Figure 5). If it does not come to a change of the sign at any of these shifts, the knowledge is not interesting from the investment decision making point of view because the initial decision will not be influenced by it.

In the opposite case from the acceptable price of information point of view what is interesting is the value $\mathrm{P}$ of the overhanging arrow $\Delta \mathrm{E}$ behind the point 0 on the NPV axis in Figure 5, which is also the upper limit of the acceptable price of the knowledge. It indicates the possibility that the knowledge changes the initial decision, by which it comes to the expected saving (or income) worth of $\mathrm{P}$ compared to the decision without the knowledge. This consideration is also 
valid in the case of $E\left[\mathrm{NPV}_{\mathrm{I}}\right]<0$ (then the points $\mathrm{NPV}_{\mathrm{pes}}, \mathrm{E}\left[\mathrm{NPV} \mathrm{V}_{\mathrm{I}}\right]$ and $\mathrm{NPV}_{\text {opt }}$ including the arrows $\Delta \mathrm{E}$ will be shifted to the left in Figure 5 and the $\mathrm{P}$ overhanging reaches the positive half axis NPV). We include both possibilities by assigning $\mathrm{P}=\Delta \mathrm{E}-\left|\mathrm{E}\left[\mathrm{NPV}_{\mathrm{I}}\right]\right|$ and then we consider only the nonnegative $\mathrm{P}$ values.

\section{The link of the wealth utility with the uncertainty and risk of an investment}

The criterion of the economic choice is the utility maximization. The decision about accepting or refusing the investment $I$ is a choice between two commodities: The certain wealth (the variable $M$ ) and the estimated wealth that is uncertain (the variable $E\left[M_{I}\right]$ ) whereas from the equality of both variables does not result the equality of utility. And so the potential investor decides according to his higher utility perception: that is he decides between the current wealth $\mathrm{M}_{0}$ and the expected total wealth $E\left[\mathrm{M}_{\mathrm{I}}\right]=\mathrm{M}_{0}+\mathrm{E}[\mathrm{NPV} \mathrm{I}]$ promised by the investment. The ordinarily used rule NPV generalized to $\mathrm{E}[\mathrm{NPV}]$ advises to refuse the investment if $\mathrm{E}[\mathrm{NPV} \mathrm{I}]<0$ and to invest if $\mathrm{E}\left[\mathrm{NPV}_{\mathrm{I}}\right]>0$. If the fact that $\mathrm{M}_{0}$ is certain and $\mathrm{E}\left[\mathrm{M}_{\mathrm{I}}\right]$ uncertain is irrelevant on terms of growing wealth utility, it would be surely the right generalization. However, people rarely appraise the certain and the uncertain things equally (as the proverb goes "a bird in the hand is worth two in the bush").

To show where the generalization of the rule NPV to E[NPV] is or is not in agreement with the utility maximization criterion is one of the aims of this contribution. Below we proceed from the cardinal conception of the wealth utility that as we suppose is measurable and expressible by the function $\mathrm{u}: \mathrm{R} \rightarrow \mathrm{R}$, in which the negative values of the wealth $\mathrm{M}$ mean a debt and the negative values of utility $U$ mean a detriment.

\subsection{The current (certain) and the expected (uncertain) utility}

The hatched curve line $\mathrm{u}_{\mathrm{M}}$ in Figure 4 illustrates the dependability of certain utility values $\mathrm{U}(\mathrm{M})$ on the nonnegative values of the certain wealth $\mathrm{M}$. Its concave shape is consistent with the principle of a diminishing marginal utility which says that from a certain amount of wealth the additional satisfaction obtained from the last added unit of a commodity is diminishing. For uncertain expected values of unbiased estimates regarding the investment $I$ it holds:

$$
\begin{gathered}
\mathrm{E}\left[\mathrm{M}_{\mathrm{I}}\right]=\mathrm{p} \cdot \mathrm{M}_{\mathrm{opt}}+(1-\mathrm{p}) \cdot \mathrm{M}_{\mathrm{pes}}=\mathrm{M}_{\mathrm{pes}}+\mathrm{p} \cdot\left(\mathrm{M}_{\mathrm{opt}}-\mathrm{M}_{\mathrm{pes}}\right) \\
\mathrm{E}\left[\mathrm{U}_{\mathrm{I}}\right]=\mathrm{p} \cdot \mathrm{U}\left(\mathrm{M}_{\mathrm{opt}}\right)+(1-\mathrm{p}) \cdot \mathrm{U}\left(\mathrm{M}_{\mathrm{pes}}\right)=\mathrm{U}\left(\mathrm{M}_{\mathrm{pes}}\right)+\mathrm{p} \cdot\left(\mathrm{U}\left(\mathrm{M}_{\mathrm{opt}}\right)-\mathrm{U}\left(\mathrm{M}_{\mathrm{pes}}\right)\right) \text {, where } 0 \leq \mathrm{p} \leq 1
\end{gathered}
$$


The foregoing system of relations is the parametric equation of the line segment marked as $\mathrm{u}_{\mathrm{E}}$ with extreme points $\left(\mathrm{M}_{\mathrm{pes}}, \mathrm{U}\left(\mathrm{M}_{\mathrm{pes}}\right)\right)$ and $\left(\mathrm{M}_{\mathrm{opt}}, \mathrm{U}\left(\mathrm{M}_{\mathrm{opt}}\right)\right)$ in Figure 4. By elimination the parameter $\mathrm{p}$ the dependence $\mathrm{E}\left[\mathrm{U}_{\mathrm{I}}\right]$ on $\mathrm{E}\left[\mathrm{M}_{\mathrm{I}}\right]$ can be formulated explicitly:

$$
\mathrm{E}\left[\mathrm{U}_{\mathrm{I}}\right]=\mathrm{U}\left(\mathrm{M}_{\mathrm{pes}}\right)+\left(\mathrm{U}\left(\mathrm{M}_{\mathrm{opt}}\right)-\mathrm{U}\left(\mathrm{M}_{\mathrm{pes}}\right)\right) \cdot\left(\mathrm{E}\left[\mathrm{M}_{\mathrm{I}}\right]-\mathrm{M}_{\mathrm{pes}}\right) /\left(\mathrm{M}_{\mathrm{opt}}-\mathrm{M}_{\mathrm{pes}}\right)
$$

So derived function $\mathrm{u}_{\mathrm{E}}:\left\langle\mathrm{M}_{\text {pes }}, \mathrm{M}_{\mathrm{opt}}\right\rangle \rightarrow\left\langle\mathrm{U}\left(\mathrm{M}_{\text {pes }}\right), \mathrm{U}\left(\mathrm{M}_{\mathrm{opt}}\right)\right\rangle$ defines the expected utility $\mathrm{E}\left[\mathrm{U}_{\mathrm{I}}\right]$ of the expected wealth $E\left[\mathrm{M}_{\mathrm{I}}\right]$.

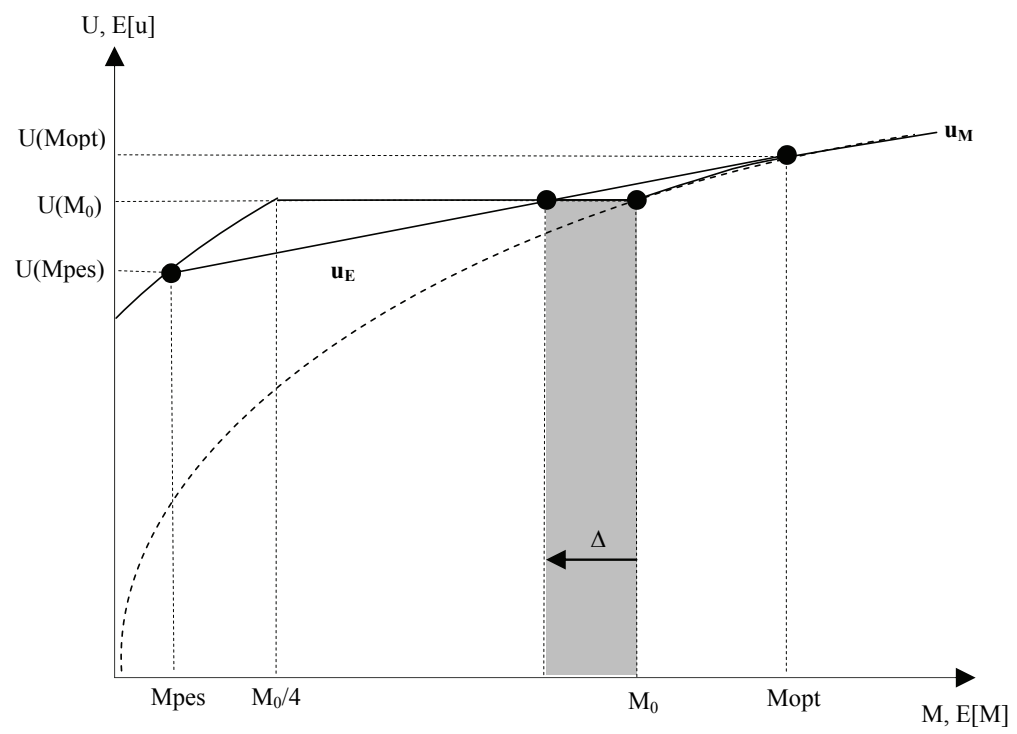

Fig. 7. The analysis of investments of the state-guaranteed deposits

Source: own model.

The generalization NPV to E[NPV] leads to the approximation of function $\mathrm{u}_{\mathrm{M}}$ with line segment $u_{E}$ over the interval $\left\langle M_{\text {pes }}, M_{\text {opt }}\right\rangle$. The excess of $u_{M}$ over $u_{E}$ says that the investor prefers the certainty to the uncertainty which is explained as the risk aversion ${ }^{15}$. It is also possible to imagine the investor (or rather the "gambler") with a risk-proclivity who does not regard the uncertainty as danger but as opportunity ${ }^{16}$. His curve $u_{M}$ over the interval $\left\langle\mathrm{M}_{\text {pes }}, \mathrm{M}_{\text {opt }}\right\rangle$ would be of a convex shape. In case of a risk neutral investor, $u_{M}$ and $u_{E}$ would join. Under certain circumstances there could alternate the sections of the risk aversion and the risk proclivity over the interval $\left\langle\mathrm{M}_{\text {pes }}, \mathrm{M}_{\mathrm{opt}}\right\rangle$ (see Figure 7). 


\subsection{The rule $E[N P V]$ versus the maximization utility criterion}

In Figure 4 we can see that the utility of the current wealth $M_{0}$ is $U\left(M_{0}\right)$. This utility the investor retains when he does not invest. The investment $I$ offers to him a "statistically reasonable" chance of increasing this utility in case of $E\left[M_{I}\right]=M_{0}+E\left[N P V_{I}\right]>M_{0}+\Delta$, that is when $\mathrm{E}\left[\mathrm{NPV}_{\mathrm{I}}\right]>\Delta$. Within the interval $\left\langle\mathrm{M}_{0}, \mathrm{M}_{0}+\Delta\right)$ the investors consider the uncertain estimated wealth $\mathrm{E}\left[\mathrm{M}_{\mathrm{I}}\right]$ as less useful than the current wealth that is unburdened with uncertainty. In their eyes it shifts (because of the utility maximization) the decision breaking point about $\Delta$ to the right (in the case of accepting the project at $0<\mathrm{E}[\mathrm{NPV}]<\Delta$ the expected utility of the investors' wealth would be lower than the current wealth of refusing the project). The size of $\Delta$ shift depends on the position of $\mathrm{M}_{0} \in\left\langle\mathrm{M}_{\text {pes }}, \mathrm{M}_{\text {opt }}\right\rangle$ and it achieves its maximum if the tangent line to the curve $u_{M}$ at the point $\left(M_{0}, U\left(M_{0}\right)\right)$ is parallel to the line $u_{E}$, that is if at the point $M_{0}$ it holds : $\mathrm{dU} / \mathrm{dM}=\left(\mathrm{U}\left(\mathrm{M}_{\mathrm{opt}}\right)-\mathrm{U}\left(\mathrm{M}_{\mathrm{pes}}\right)\right) /\left(\mathrm{M}_{\mathrm{opt}}-\mathrm{M}_{\mathrm{pes}}\right)$.

The decision breaking point shift influences investment decisions of banks and others institutionalized investors negatively in case the state guarantees the savers' deposits. In Figure 7 we analyze the case of refunding the loss to the extend of $75 \%$ of all the deposits by the state.

On the horizontal axis in Figure 7 there are plotted present values of the total amount of deposits where $\mathrm{M}_{0}$ stands for the initial situation. If the state does not guarantee the deposits the utility curve $\mathrm{u}_{\mathrm{M}}$ of the deposits would take a hatched course to the left of $\mathrm{M}_{0}$. However, by guaranteeing the deposits the state commits to refund the loss caused by unprofitable investments to the savers in the full amount out of its resources if it does not exceed the $75 \%$ of $\mathrm{M}_{0}$ value. As a result of this refunding, $U(M)=U\left(M_{0}\right)$ for $M \in\left\langle M_{0} / 4, M_{0}\right\rangle$ and the hatched curve $u_{M}$ is replaced with the full line located over it. The line $u_{E}$ that approximates $u_{M}$ over the interval $\left\langle M_{\text {pes }}\right.$, $\left.\mathrm{M}_{\mathrm{opt}}\right\rangle$ causes the shift of the decision breaking point about $\Delta$ again but now to the left. The utility maximization thus make banks invest in the unprofitable products with $-\Delta<\mathrm{E}\left[\mathrm{NPV}_{\mathrm{I}}\right]<0$ (at the expense of the state budget). In these cases the local utility maximization in banks view leads to the uneconomical funds allocation from the state point of view as a whole. This pulls the state economy into the globally unfavorable condition.

\section{Conclusions}

The aim of the contribution is to point out the following fact: The generalization of the rule NPV (for the one-result investments choice) to the E[NPV] (for the more result investments choice) results in a partial split of the utility function $u$ in the pair of functions $\left(u_{M}, u_{E}\right)$. That leads to the incidence of incongruity intervals of the length $\Delta$ (see the width of the grey-colored 
columns in Figures 4 and 7) between the E[NPV] rule and the wealth maximization utility criterion. Consequently the private investors focused on the wealth utility maximization neglect the suitable capital opportunities when $0<\mathrm{E}[\mathrm{NPV}]<\Delta$, whereas like-focused institutionalized investors, in which savers' deposits are guaranteed by the state, are motivated to risk-proclivity ${ }^{17}$ and hence they invest in the unprofitable products when $-\Delta<\mathrm{E}\left[\mathrm{NPV}_{\mathrm{I}}\right]<0$.

The shift of the decision breaking point about $\Delta$ to the left or right of the breaking point $\mathrm{E}[\mathrm{NPV}]=0$ in case of investors who prefer the utility maximization of wealth to a pure maximization of wealth influences also pricing of the information. In what way? It is obvious from Figure 8 that indicates the relation between Figure 5 and Figures 4 and 7 .
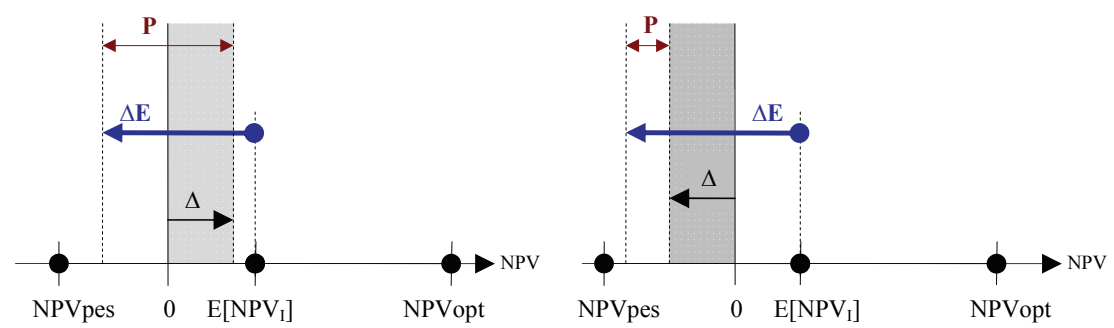

Fig. 8. The illustration of how pricing of information is influenced by the breaking point shift Source: own model.

We can see that the shift about $\Delta$ to the right marks the price of information up from the investor point of view (it makes it more desirable), the shift about $\Delta$ to the left depreciates it (it makes it less desirable because it does not depend on the quality of the decision too much in this case).

\section{Notes}

${ }^{1}$ Brealey, Myers, Marcus (2011).

${ }^{2}$ Varian (1992).

${ }^{3}$ Dvořák (2008); Kohout (2010).

${ }^{4}$ Varian (1992).

${ }^{5}$ Hašková (2010).

${ }^{6}$ Brealey, Myers, Marcus (2011).

${ }^{7}$ Varian (1992).

${ }^{8}$ Hašková (2010). 
9 The symbols „, “and „०“ in the algebraic expression for $I$ denotes a binary relation induced by the investment $I$. The first relation introduces the connections to the outcomes, of which just one can occur at the investment to $I$ (it chooses them out of the consideration domain and it is represented graphically in the figure 1 by the pair of protruding arrows that direct to the outcomes). The second one connects the relevant outcome with its probability of occurrence within $I$ and it is represented graphically in the figure 1 by attaching the probabilities to the arrows. It is not possible to mix up these symbols with the symbols of arithmetic operation for addition $(+)$ and multiplication $(\cdot)$ if we do not want to change or loose utterly the original sense of the expression.

${ }^{10}$ Varian (1992).

11 Jaglom, Jaglom (1964).

${ }^{12}$ Neumann, Morgenstern (1953).

${ }^{13}$ Hašková (2010).

${ }^{14} \Delta \mathrm{E}\left[\mathrm{NPV}_{\mathrm{I}}\right]=\mathrm{E}\left[\mathrm{NPV}_{\mathrm{I}}\right]^{\prime}-\mathrm{E}\left[\mathrm{NPV}_{\mathrm{I}}\right]=\left((0.5+\Delta \mathrm{p}) \cdot \mathrm{NPV}_{\mathrm{opt}}+(0.5-\Delta \mathrm{p}) \cdot \mathrm{NPV}_{\mathrm{pes}}\right)-\left(0.5 \cdot \mathrm{NPV}_{\mathrm{opt}}+0.5 \cdot \mathrm{NPV}_{\mathrm{pes}}\right)=$ $=\Delta \mathrm{p} \cdot\left(\mathrm{NPV}_{\text {opt }}-\mathrm{NPV}_{\text {pes }}\right)$, where $\mathrm{E}\left[\mathrm{NPV}_{\mathrm{I}}\right]^{\prime}$ is a new estimate $\mathrm{E}[\mathrm{NPV}]$ after getting the knowledge and $\Delta \mathrm{p} \in\langle-0.5,0.5\rangle$. If we supply $|\Delta \mathrm{p}|$ for $\Delta \mathrm{p}$ to the relation we get the absolute value $\left|\Delta \mathrm{E}\left[\mathrm{NPV}_{\mathrm{I}}\right]\right|$ instead of $\Delta \mathrm{E}\left[\mathrm{NPV}_{\mathrm{I}}\right]$.

${ }^{15}$ Frank (2009); Neumann, Morgenstern (1953).

${ }^{16}$ Neumann, Morgenstern (1953).

${ }^{17}$ Frank (2009).

\section{References}

Brealey, R.A., Myers, S.C. \& Marcus, A.J. (2011). Fundamentals of Corporate Finance (7th Rev. Ed). United States of America: Mcgraw-hill Education.

Dvořák, P. (2008). Veřejné finance, fiskální nerovnováha a finanční krize. Praha: C.H. Beck.

Frank, R.H. (2009). The Return of the Economic Naturalist. London: Virgin Books.

Hašková, S. (2010). The Fundamentals of Theory and Praxis of Managerial calculations. Dissertation, University of Economics in Prague, FMVŠE, Czech Republic. www.vse.cz/ vskp/21678_Z.

Jaglom, A.M. \& Jaglom, I.M. (1964). Probability and Information. Praha: Nakladatelství ČSAV.

Kohout, P. (2010). Finance po krizi. Praha: Grada Publishing, a.s.

Von Neumann, J. \& Morgenstern, O. (1953). Theory of Games and Economic Behavior. United States of America: Princeton University Press.

Varian, H.R. (1992). Microeconomic Analysis (3rd Ed.). United States of America: W.W. Norton \& Company, Inc. 